\title{
NEUROPROTECTIVE ROLE OF ASCORBIC ACID: ANTIOXIDANT AND NON-ANTIOXIDANT FUNCTIONS
}

\author{
ARUN KUMAR, REENA V SAINI*, ADESH K SAINI* \\ Center of Research on Himalayan Sustainability and Development, Faculty of Applied Sciences and Biotechnology, Shoolini University of \\ Biotechnology and Management Sciences, Solan, Himachal Pradesh, India. Email: sainiade@gmail.com, reenavohra10@gmail.com
}

Received: 16 May 2018, Revised and Accepted: 14 June 2018

\begin{abstract}
Ascorbic acid (AA) or Vitamin C is an important antioxidant which participates in numerous cellular functions. Although in human plasma its concentration is in micromolars but it reaches millimolar concentrations in most of the human tissues. The high ascorbate cellular concentrations are generated and maintained by a specific sodium-dependent Vitamin C transporter type 2 (SVCT2, member of Slc23 family). Metabolic processes recycle Vitamin C from its oxidized forms (ascorbate) inside the cells. AA concentration is highest in the neurons of the central nervous system (CNS) of mammals, and deletion of its transporter affects mice brain and overall survival. In the CNS, intracellular ascorbate serves several functions including antioxidant protection, peptide amidation, myelin formation, synaptic potentiation, and protection against glutamate toxicity. SVCT2 maintains neuronal ascorbate content in CNS which has relevance for neurodegenerative diseases such as Alzheimer's, Parkinson's, and Huntington's disease. As ascorbate supplements decrease infarct size in ischemia-reperfusion injury and protect neurons from oxidative damage, it is a vital dietary antioxidant. The aim of this review is to assess the role of the SVCT2 in regulating neuronal ascorbate homeostasis in CNS and the extent to which ascorbate affects brain function as an antioxidant.
\end{abstract}

Keywords: Vitamin C, Neurodegeneration, Nutrition, Oxidative stress, Central nervous system.

(C) 2018 The Authors. Published by Innovare Academic Sciences Pvt Ltd. This is an open access article under the CC BY license (http://creativecommons. org/licenses/by/4. 0/) DOI: http://dx.doi.org/10.22159/ajpcr.2018.v11i10.27318

\section{INTRODUCTION}

Ascorbic acid (AA), Vitamin C, is a water-soluble molecule concentrated predominately in citrus fruits, strawberries, and vegetables (e.g., spinach and broccoli). It is also synthesized by most plants and animals, with the exception of humans and some animal species. Human has mutation in the gene encoding for terminal enzyme L-gulono-1,4-lactone oxidase (EC 1.1.3.8) required in the biosynthetic pathway to yield AA from glucose [1]. Thus, humans require a constant stream of AA from the diet and rely on robust "carrier" transport and "barrier" integrity mechanisms to meet the brain's demand [2]. AA is the most powerful water-soluble first line of antioxidant defense under many types of oxidizing conditions which protects against oxidative stress and induced cellular damage by neutralization of lipid hydroperoxyl radicals [3]. During aging process, production of free radicals, antioxidant depletion, oxidative and nitrosative stress, vascular diseases, and cognitive impairments lead to dementia (Alzheimer's type). Alzheimer's disease (AD) is characterized by an insidious progressive nature that usually begins with memory deficits followed by disturbances in other cognitive domains that eventually reach a level that impacts the functions of daily life. Deficiency of Vitamin $\mathrm{C}$ in the diet results in the disease scurvy making it an important dietary component. High levels of ascorbate (the reduced form of Vitamin C) accumulation in plasma and tissues of humans help against oxidative damage and limit inflammation. Ascorbate facilitates the reduction of $\mathrm{Fe}^{3+}$ or $\mathrm{Cu}^{2+}$ in the active sites of enzymes, providing electrons used either in the hydroxylation of the enzymes-substrates or the maintenance of the active-site metal ion in the reduced state [4].

\section{VITAMIN C AND ITS TRANSPORT IN BRAIN}

Vitamin $\mathrm{C}$ is an essential nutrient for the functioning of nervous system because of its role in defense against oxidative stress and formation of important biocomponents such as myelin, peptide hormones, and tyrosine. Ascorbate concentration is $1-2 \mathrm{mM}$ in the whole brain while it is much higher in intracellular neuronal concentrations [5]. Having 10fold higher rates of oxidative metabolism than supporting glia, neurons are sensitive to ascorbate deficiency [6]. High concentration of ascorbate in cerebrospinal fluid CSF and neurons is maintained by homeostatic mechanism which has neuroprotective role [7]. Depriving ascorbate for 14 days from diet, guinea pig brains still had $24 \%$ of their original ascorbate content, relating to the fact that ascorbate is avidly retained by the central nervous system (CNS) during ascorbate deficiency [8]. Catecholamine synthesis is decreased if sodium-dependent Vitamin C transporter type 2 (SVCT2) transporter fails to maintain high ascorbate concentration in CSF and neuronal cells $[9,10]$.

The ischemia-reperfusion injury that occurs with stroke in CNS due to oxidative stress and generation of reactive oxygen species (ROS) depletes intracellular GSH, and ascorbate in the brain leads to tissue damage in CNS [11]. Occlusion of the middle cerebral artery after $15 \mathrm{~min}$ or $3 \mathrm{~h}$ of high-dose administration with dehydroascorbate given by intraperitoneal injection markedly decreases infarct volume, mortality, and neurological deficits in mice and shows rapid transport of dehydroascorbate across the blood-brain barrier by glucose transporters [12,13]. Due to the lack of SVCT2 in endothelial cells, ascorbate does not cross the blood-brain barrier in its fully reduced form and thus unable to treat neuronal damage in rat model shown by in situ hybridization [14,15]. Increased intracellular ascorbate content of rat brain decreased the swelling induced by oxidant stress and also prevented the loss of alpha-tocopherol and lipid peroxidation induced by culture in oxygenated medium $[16,17]$.

Glutamate uptake by neurons and glia is associated with ischemic release of AA from brain cells in large amounts and considerably increased the ascorbate efflux from cerebral astrocytes [18,19]. Ascorbate is well known to be involved in neuronal biochemistry (e.g., peptide amidation, myelination, and catecholamine synthesis). Maturation of cultured embryonic cortical precursor cells into neurons and astrocytes in medium containing ascorbate was first shown by Lee et al. [20], and further confirmation was done in primary cultures of hippocampal neurons by Qiu et al. [21]. Ascorbate enters neurons and glia by two mechanisms, first by transport of ascorbate on the SVCT2 and second 
by uptake and reduction of dehydroascorbate. Ascorbate transport from plasma across the choroid plexus to the CSF and neuronal cell plasma membrane is mediated by SVCT2 transport [22,23]. DHA enters the CNS more rapidly than ascorbate, but after oral administration, ascorbate readily penetrates the CNS [24].

Supplementation of $1 \mathrm{~g}$ Vitamin $\mathrm{C}$ a day increases plasma levels from $50 \mu \mathrm{M}$ to $70 \mu \mathrm{M}$ and CSF ascorbate level from $200 \mu \mathrm{M}$ to $250 \mu \mathrm{M}$ [23]. Neuronal ascorbate concentration in rat models has been calculated to be as high as $10 \mathrm{mM}$, whereas glial ascorbate found to be $0.9 \mathrm{mM}$ [5]. Histochemical studies of the brain show that much of ascorbate accumulates in neurons [25]. In situ hybridization studies in rat brain implicate that SVCT2 mRNA is present only in neurons and not in astrocytes $[14,26]$. SVCT2 mRNA is expressed in certain glial elements in the hypothalamus of the brain in more recent studies [15]. The second route for ascorbate to enter the CNS is through transport of dehydroascorbate across the blood-brain barrier on the ubiquitous GLUT1 glucose transporter. Any generated ascorbate in the brain interstitium would also be taken up by GLUT1 and GLUT3 in glia and neurons. DHA enters both glia and neurons on glucose transporters in substantial amounts where it rapidly reduces to ascorbate which serves as a backup mechanism to recover oxidized ascorbate before it is lost with degradation of DHA. Recently, this mechanism in cultured HL-60 cells has been termed as "bystander" effect [27].

AA concentration is higher in the human brain and adrenal glands. Deficiency of AA results in classical clinical syndrome, scurvy, particularly in populations such as the elderly and hospitalized and those with poor access to good nutrition [28]. Even smokers require high intakes of AA which works as good antioxidant. Arterial elasticity and blood pressure regulation through recycling of the endothelial nitric oxide synthase cofactor and tetrahydrobiopterin are regulated by AA [29]. It is presumed that oxidative stress induced by glutamate is moderated by AA and so is protective against overstimulation and cell death [30]. Postmortem samples of patients with hippocampal sclerosis and AD show altered glutamate transport (e.g., changes in EAAT2 and EAAT3 transporters) in the brain [31]. For rapid removal of glutamate from the synapse, GLT-1 transporter relies on Na-dependent transport across an electrochemical gradient. It is sensitive to oxidative stress, and disruption of the GLT-1 transporter leads to glutamate accumulation and hyperstimulation of receptors. Memantine drug for AD blocks NMDA receptors through glutamate transport which suggests further research into glutamatergic signaling and high intracellular AA levels in the brain [32].

\section{AA PREVENTS NEURONAL DAMAGE}

Brain cells face challenges of the high rate of cellular metabolism, especially, mitochondria and high concentration of unsaturated fatty acids which leads to increased levels of free radicals and thus oxidative stress. Vitamin C directly neutralizes oxidative and nitrosative stresscausing agents, and interestingly, it also recycles Vitamin E which is involved in neutralizing peroxyl radicals which prevents peroxidation of lipids. These facts make AA as a highly protective agent in the brain. In addition to its role in the synthesis of neurotransmitters such as dopamine and norepinephrine, AA also helps in the binding of neurotransmitters to their receptors [33-38]. Hyperpolarization of the receptor for $\mathrm{N}$-methyl-D-aspartate owing to excessive levels of extracellular glutamate could lead to excitotoxic damage. It has been shown that AA prevents the binding of glutamate to the receptor of N-methyl-D-aspartate and thus prevents neuronal damage by decreasing nerve stimulation [39].

High AA concentration in CSF and brain parenchyma has recently generated interest in the field of epigenetics to rule out AA function in the brain. AA is a critical cofactor (needed for the reduction of iron $\mathrm{Fe}^{3+}$ to its active form $\mathrm{Fe}^{2+}$ ) for the activity of TET (ten-eleven translocation) dioxygenase enzyme which oxidizes 5-mc (5-methylcytosine) to 5-hmc (hydroxymethylcytosine) as a part of dynamic DNA demethylation [40].
Thus, AA is vital for neuronal repair as well as new cell generation and may play a direct role in the transcription and expression of hundreds of different genes. TET proteins and 5-hmc are abundant in brain and knockout of Tet1 in mice indicated that it may be involved in synaptic plasticity and memory extinction in addition to DNA methylation [41].

\section{AA AND BRAIN DISEASES}

An investigation by Warner et al. showed that if heterozygous mutation is created in SVCT2 gene in mice, it leads to decreased Vitamin C levels in body and increased oxidative stress in brain cells [42]. Another important study in mice carrying human AD mutations in APP and PSEN1 genes (coding for amyloid precursor protein and presenilin, respectively) and heterozygous mutation in $\mathrm{SVCT}^{+/-}$gene increases the oxidative stress. A slight decrease of Vitamin $\mathrm{C}$ in the mice brain hastens the aggregation of amyloid and increases oxidative stress in the brain [43]. Another proof comes from the study where gulo knockout mice (lacking enzyme required to synthesize Vitamin C) showed higher oxidative stress and reduced dopamine and serotonin levels [44].

Clinical studies in human have shown that patient's with Parkinson's disease and multiple sclerosis have intracellular deficiency of Vitamin C [45-48]. In Parkinson's disease, one of the factors is excitotoxicity by glutamate, and as mentioned earlier, glutamate excitotoxicity can be taken care by AA as shown in the in vitro results [30]. Vitamin $C$ has been shown to reduce indirectly the oligomerization of alpha-synuclein by working as an antioxidant $[49,50]$. It has been shown that dietary intake of Vitamin C reduces the risk of Parkinson's disease. Besides brain disorders, Vitamin $\mathrm{C}$ has also been shown to be involved in psychiatric disorders such as depression, stress, anxiety, and other in humans. Animal studies have shown that Vitamin $\mathrm{C}$ employs antidepressant-like effects by activating 5-HT1A, GABA, N-methyl-Daspartate receptors [51-53].

\section{CONCLUSIONS}

Antioxidant nature of plant-based compounds plays a significant role in controlling many ailments including the dreadful cancer [54-56]. Vitamin C, a known antioxidant, exerts its effects both through acting as antioxidant and through non-antioxidant effect. Being an electron donor, AA readily reacts with a range of ROS to neutralize or decrease their reactivity. This leads to the formation of the ascorbate free radical, which can be efficiently recycled to AA through enzymatic means. Evidences are increasing which shows that Vitamin $\mathrm{C}$ along with Vitamin E helps in improving brain function by reducing oxidative damage. In its non-antioxidant function, it directly affects the activity of neurotransmitters by modulating their binding to their receptors and thus prevents neurodegeneration and psychiatric disorders.

\section{ACKNOWLEDGMENTS}

We would like to thank the Department of Science and Technology, Government of India, Grant [Int/NZ/P-2/13] to AKS.

\section{AUTHOR'S CONTRIBUTION}

AK and RVS have written the manuscript. AKS has done modification and editing.

\section{CONFLICTS OF INTEREST}

The authors declared that they have no conflicts of interest.

\section{REFERENCES}

1. Nishikimi M, Fukuyama R, Minoshima S, Shimizu N, Yagi K. Cloning and chromosomal mapping of the human nonfunctional gene for L-gulono-gamma-lactone oxidase, the enzyme for L-ascorbic acid biosynthesis missing in man. J Biol Chem 1994;269:13685-8.

2. Frei B, England L, Ames BN. Ascorbate is an outstanding antioxidant in human blood plasma. Proc Natl Acad Sci U S A 1989;86:6377-81.

3. Berger TM, Polidori MC, Dabbagh A, Evans PJ, Halliwell B, 
Morrow JD, et al. Antioxidant activity of vitamin C in iron-overloaded human plasma. J Biol Chem 1997;272:15656-60.

4. Prince M, Bryce R, Albanese E, Wimo A, Ribeiro W, Ferri CP, et al. The global prevalence of dementia: A systematic review and metaanalysis. Alzheimers Dement 2013;9:63-75.

5. Rice ME. Ascorbate regulation and its neuroprotective role in the brain. Trends Neurosci 2000;23:209-16.

6. Wilson JX. Antioxidant defense of the brain: A role for astrocytes. Can J Physiol Pharmacol 1997;75:1149-63.

7. Hediger MA. New view at C. Nat Med 2002;8:445-6.

8. Hughes RE, Hurley RJ, Jones PR. The retention of ascorbic acid by guinea-pig tissues. Br J Nutr 1971;26:433-8.

9. Bornstein SR, Yoshida-Hiroi M, Sotiriou S, Levine M, Hartwig HG, Nussbaum RL, et al. Impaired adrenal catecholamine system function in mice with deficiency of the ascorbic acid transporter (SVCT2). FASEB J 2003;17:1928-30.

10. Gould DB, Phalan FC, Breedveld GJ, van Mil SE, Smith RS, Schimenti JC, et al. Mutations in col4a1 cause perinatal cerebral hemorrhage and porencephaly. Science 2005;308:1167-71.

11. Rice ME, Lee EJ, Choy Y. High levels of ascorbic acid, not glutathione, in the CNS of anoxia-tolerant reptiles contrasted with levels in anoxiaintolerant species. J Neurochem 1995;64:1790-9.

12. Huang J, Agus DB, Winfree CJ, Kiss S, Mack WJ, McTaggart RA, et al. Dehydroascorbic acid, a blood-brain barrier transportable form of vitamin C, mediates potent cerebroprotection in experimental stroke. Proc Natl Acad Sci U S A 2001;98:11720-4

13. Mack WJ, Mocco J, Ducruet AF, Laufer I, King RG, Zhang Y, et al. A cerebroprotective dose of intravenous citrate/sorbitol-stabilized dehydroascorbic acid is correlated with increased cerebral ascorbic acid and inhibited lipid peroxidation after murine reperfused stroke. Neurosurgery 2006;59:383-8.

14. Berger UV, Lu XC, Liu W, Tang Z, Slusher BS, Hediger MA, et al. Effect of middle cerebral artery occlusion on mRNA expression for the sodium-coupled vitamin C transporter SVCT2 in rat brain. J Neurochem 2003;86:896-906.

15. García Mde L, Salazar K, Millán C, Rodríguez F, Montecinos H, Caprile T, et al. Sodium vitamin C cotransporter SVCT2 is expressed in hypothalamic glial cells. Glia 2005;50:32-47.

16. Brahma B, Forman RE, Stewart EE, Nicholson C, Rice ME. Ascorbate inhibits edema in brain slices. J Neurochem 2000;74:1263-70.

17. Li X, Huang J, May JM. Ascorbic acid spares alpha-tocopherol and decreases lipid peroxidation in neuronal cells. Biochem Biophys Res Commun 2003;305:656-61.

18. Hillered L, Persson L, Bolander HG, Hallström A, Ungerstedt U. Increased extracellular levels of ascorbate in the striatum after middle cerebral artery occlusion in the rat monitored by intracerebral microdialysis. Neurosci Lett 1988;95:286-90.

19. Wilson JX, Peters CE, Sitar SM, Daoust P, Gelb AW. Glutamate stimulates ascorbate transport by astrocytes. Brain Res 2000;858:61-6.

20. Lee JY, Chang MY, Park CH, Kim HY, Kim JH, Son H, et al. Ascorbateinduced differentiation of embryonic cortical precursors into neurons and astrocytes. J Neurosci Res 2003;73:156-65.

21. Qiu S, Li L, May JM. Ascorbate transport by primary cultured neurons and its role in neuronal function and protection against excitotoxicity. J Neurosci Res 2006. (In Press).

22. Reiber $H$, Ruff $M$, Uhr $M$. Ascorbate concentration in human cerebrospinal fluid (CSF) and serum. Intrathecal accumulation and CSF flow rate. Clin Chim Acta 1993;217:163-73.

23. Lönnrot K, Metsä-Ketelä T, Molnár G, Ahonen JP, Latvala M, Peltola J, et al. The effect of ascorbate and ubiquinone supplementation on plasma and CSF total antioxidant capacity. Free Radic Biol Med 1996;21:211-7.

24. Kontush A, Mann U, Arlt S, Ujeyl A, Lührs C, Müller-Thomsen T, et al. Influence of vitamin $\mathrm{E}$ and $\mathrm{C}$ supplementation on lipoprotein oxidation in patients with Alzheimer's disease. Free Radic Biol Med 2001;31:345-54

25. Shimizu N, Matsunami T, Onishi S. Histochemical demonstration of ascorbic acid in the locus coeruleus of the mammalian brain. Nature 1960;186:479-80.

26. Castro M, Caprile T, Astuya A, Millán C, Reinicke K, Vera JC, et al. High-affinity sodium-vitamin C co-transporters (SVCT) expression in embryonic mouse neurons. J Neurochem 2001;78:815-23.

27. Nualart FJ, Rivas CI, Montecinos VP, Godoy AS, Guaiquil VH, Golde DW, et al. Recycling of vitamin C by a bystander effect. J Biol Chem 2003;278:10128-33.

28. Raynaud-Simon A, Cohen-Bittan J, Gouronnec A, Pautas E, Senet P, Verny M, et al. Scurvy in hospitalized elderly patients. J Nutr Health Aging 2010;14:407-10.
29. Kaliora AC, Dedoussis GV, Schmidt H. Dietary antioxidants in preventing atherogenesis. Atherosclerosis 2006;187:1-7.

30. Ballaz S, Morales I, Rodriguez M, Obeso JA. Ascorbate prevents cell death from prolonged exposure to glutamate in an in vitro model of human dopaminergic neurons. J Neurosci Res 2013;91:1609-17.

31. Proper EA, Hoogland G, Kappen SM, Jansen GH, Rensen MG, Schrama LH, et al. Distribution of glutamate transporters in the hippocampus of patients with pharmaco-resistant temporal lobe epilepsy. Brain 2002;125:32-43.

32. Rebec GV, Barton SJ, Marseilles AM, Collins K. Ascorbate treatment attenuates the Huntington behavioral phenotype in mice. Neuroreport 2003;14:1263-5.

33. Majewska MD, Bell JA, London ED. Regulation of the NMDA receptor by redox phenomena: Inhibitory role of ascorbate. Brain Res 1990;537:328-32.

34. Rebec GV, Pierce RC. A vitamin as neuromodulator: Ascorbate release into the extracellular fluid of the brain regulates dopaminergic and glutamatergic transmission. Prog Neurobiol 1994;43:537-65.

35. Serra PA, Esposito G, Delogu MR, Migheli R, Rocchitta G, Grella G, et al. Analysis of 3-morpholinosydnonimine and sodium nitroprusside effects on dopamine release in the striatum of freely moving rats: Role of nitric oxide, iron and ascorbic acid. Br J Pharmacol 2000;131:836-42.

36. Todd RD, Bauer PA. Ascorbate modulates $5-[3 \mathrm{H}]$ hydroxyl tryptamine binding to central 5-HT3 sites in bovine frontal cortex. J Neurochem 1988;50:1505-12.

37. Harrison FE, May JM. Vitamin C function in the brain: Vital role of the ascorbate transporter SVCT2. Free Radic Biol Med 2009;46:719-30.

38. Figueroa-Méndez R, Rivas-Arancibia S. Vitamin $\mathrm{C}$ in health and disease: It's role in the metabolism of cells and redox state in the brain. Front Physiol 2015;23:397.

39. Sandstrom MI, Rebec GV. Extracellular ascorbate modulates glutamate dynamics: Role of behavioral activation. BMC Neurosci 2007;8:32.

40. Blaschke K, Ebata KT, Karimi MM, Zepeda-Martínez JA, Goyal P, Mahapatra S, et al. Vitamin C induces tet-dependent DNA demethylation and a blastocyst-like state in ES cells. Nature 2013;500:222-6.

41. Rudenko A, Dawlaty MM, Seo J, Cheng AW, Meng J, Le T, et al. Tet1 is critical for neuronal activity-regulated gene expression and memory extinction. Neuron 2013;79:1109-22.

42. Warner TA, Kang JQ, Kennard JA, Harrison FE. Low brain ascorbic acid increases susceptibility to seizures in mouse models of decreased brain ascorbic acid transport and Alzheimer's disease. Epilepsy Res 2015;110:20-5.

43. Dixit S, Bernardo A, Walker JM, Kennard JA, Kim GY, Kessler ES, et al. Vitamin $\mathrm{C}$ deficiency in the brain impairs cognition, increases amyloid accumulation and deposition, and oxidative stress in APP/ PSEN1 and normally aging mice. ACS Chem Neurosci 2015;6:570-81.

44. Ward MS, Lamb J, May JM, Harrison FE. Behavioral and monoamine changes following severe vitamin $\mathrm{C}$ deficiency. J Neurochem 2013;124:363-75.

45. Medeiros MS, Schumacher-Schuh A, Cardoso AM, Bochi GV, Baldissarelli J, Kegler A, et al. Iron and oxidative stress in Parkinson's disease: An observational study of injury biomarkers. PLoS One 2016;11:e0146129.

46. Quiroga MJ, Carroll DW, Brown TM. Ascorbate- and zinc-responsive Parkinsonism. Ann Pharmacother 2014;48:1515-20.

47. Polachini CR, Spanevello RM, Zanini D, Baldissarelli J, Pereira LB, Schetinger MR, et al. Evaluation of delta-aminolevulinic dehydratase activity, oxidative stress biomarkers, and vitamin D levels in patients with multiple sclerosis. Neurotox Res 2016;29:230-42.

48. Tavazzi B, Batocchi AP, Amorini AM, Nociti V, D’Urso S, Longo S, et al. Serum metabolic profile in multiple sclerosis patients. Epub Mult Scler Int 2011;2011:167156

49. Covarrubias-Pinto A, Acuña AI, Beltrán FA, Torres-Díaz L, Castro MA. Old things new view: Ascorbic acid protects the brain in neurodegenerative disorders. Int J Mol Sci 2015;16:28194-217.

50. Xiang W, Schlachetzki JC, Helling S, Bussmann JC, Berlinghof M, Schaffer TE, et al. Oxidative stress-induced posttranslational modifications of $\alpha$-synuclein: Specific modification of $\alpha$-synuclein by 4-hydroxy-2-nonenal increases dopaminergic toxicity. Mol Cell Neurosci 2013;54:71-83

51. Acuña AI, Esparza M, Kramm C, Beltrán FA, Parra AV, Cepeda C, et al. A failure e in energy metabolism and antioxidant uptake precede symptoms of Huntington's disease in mice. Nat Commun 2013;4:2917.

52. Rosa PB, Neis VB, Ribeiro CM, Moretti M, Rodrigues AL. Antidepressant-like effects of ascorbic acid and ketamine involve modulation of GABAA and GABAB receptors. Pharmacol Rep 2016;68:996-1001 
53. Binfaré RW, Rosa AO, Lobato KR, Santos AR, Rodrigues AL. Ascorbic acid administration produces an antidepressant-like effect: Evidence for the involvement of monoaminergic neurotransmission. Prog Neuropsychopharmacol Biol Psychiatry 2009;33:530-40.

54. Chahal A, Saini AK, ChhillarAK, Saini RV. Natural antioxidants as defence system against cancer. Asian J Pharm Clin Res 2018;11:1-7.
55. Sharma R, Chandan G, Chahal A, Saini RV. Antioxidant and anticancer activity of methanolic extract from Stephania elegans. Int J Pharm Pharm Sci 2017;9:245-9.

56. Lalitha V, Korah MC, Sengottuvel S, Sivakumar T. Antidiabetic and antioxidant activity of resveratrol and vitamin-c combination on streptozotocin induced diabetic rats. Int J Pharm Pharm Sci 2015;7:455-8. 